\title{
Retraction
}

\section{Retracted: Adrenal Schwannomas: Rare Tumor of the Retroperitoneum}

\begin{abstract}
Case Reports in Surgery
Received 3 January 2016; Accepted 3 January 2016

Copyright (c) 2016 Case Reports in Surgery. This is an open access article distributed under the Creative Commons Attribution License, which permits unrestricted use, distribution, and reproduction in any medium, provided the original work is properly cited.
\end{abstract}

The paper titled "Adrenal Schwannomas: Rare Tumor of the Retroperitoneum" [1] has been retracted as it is found to contain a substantial amount of material, without referencing, from the article titled "Laparoscopic Resection of an Adrenal Schwannoma" by Toutouzas G. Konstantinos, Tsamis Dimitrios, Kekis B. Panagiotis, Michalopoulos V. Nikolaos, Flessas Ioannis, Manouras Andreas, and Zografos Geogrios, published in the Journal of the Society of Laparoendoscopic Surgeons.

\section{References}

[1] E. Grasso and M. Simone, "Adrenal schwannomas: rare tumor of the retroperitoneum," Case Reports in Surgery, vol. 2015, Article ID 547287, 4 pages, 2015. 